\title{
Preparation of Micro Barium Titanate Powder and Comparison with Nano Powder Properties
}

\author{
${ }^{1}$ Ghadeer S. Jassim*, ${ }^{1}$ Mojahid M. Najim, ${ }^{2}$ Wafaa Mahdi Salih \\ ${ }^{1}$ Material Branch, Department of Applied Sciences, University of Technology - Iraq \\ ${ }^{2}$ Department of Materials Engineering, University of Technology - Iraq
}

\section{Article information}

Article history:

Received: May, 21, 2021

Accepted: June, 22, 2021

Available online: December, 04, 2021

Keywords:

Fine Powder,

Scanning electron microscopy,

Solid-state reaction,

X-Ray Diffraction

*Corresponding Author:

Ghadeer S.Jassim

as.18.37@grad.uotechnology.edu.iq

\begin{abstract}
In this paper, a homogenous pure Barium Titanate with formula $\left(\mathrm{BaTiO}_{3}\right)$ was prepared from pure Barium Carbonate $\left(\mathrm{BaCO}_{3}\right)$ and titanium dioxide $\left(\mathrm{TiO}_{2}\right)$ using the solid-state reaction technique, were used as raw materials having micro size by mixing of molar ratio [1:1], the powder was calcined at temperatures $(900-1350){ }^{\circ} \mathrm{C}$. The solid-State reaction can consider as an attractive process realistic alternative to the expensive wet-chemical route, according to X-ray diffraction, all of the peaks of Barium Titanate powder were perfectly suited to the positions of the peaks of the standard tetragonal phase in the pattern for this process. And with preferred crystalline size for the powder calcined at $1350{ }^{\circ} \mathrm{C}$ manifested the best results, where all the peaks indicate the formation of Barium Titanate completely. In addition, each $\mathrm{BaTiO}_{3}$ Nanopowder was compared to a micro powder that had been manufactured, by conducting x-ray diffraction, diffraction peaks undergo shifting toward higher angle to the high value of $2 \Theta$, and Nano powder particles are smaller than micro powder particles. And this refers to a decrease in lattice parameters, in terms of the peaks of the Nano powder preceding the peaks of the micro powder of $\mathrm{BaTiO}_{3}$ and that match the result that is obtained by scanning electron microscopy (SEM).
\end{abstract}

DOI: 10.53293/jasn.2021.3653.1033, Department of Applied Sciences, University of Technology

This is an open access article under the CC BY 4.0 License.

\section{Introduction}

Barium Titanate $\left(\mathrm{BaTiO}_{3}\right)$ the first ceramic material in which ferroelectric behaviour was observed in 1945 by $\mathrm{Vul}$ and Goldman. With its much simpler structure (Perovskite), Perovskite ceramics materials are significant electronic materials in the scientific field. Barium Titanate is the first ferroelectric ceramic and it a good candidate for a range of applications due to its high dielectric and piezoelectric properties[1]. It can be prepared by several methods, depending on the desired properties of the final application. As the method used (Solid-State Reaction) has a great impact on the structure and properties of Barium Titanate materials, Because of its large dielectric constant and low loss characteristics. For that, It was widely used in many applications, including multilayer ceramic capacitors (MLCS), capacitors with high voltage, capacitors with rapid response, and is used in thin films. Most of these applications are based on the ferroelectric behaviour of Barium Titanate, dynamic random access 
memory (DRAMI), communications, filters, ultrasound transducers, and piezoelectric sensors. Pure Barium titanium is an electrical insulator, and when doped in various oxides, it can be used as semiconductors. [2-4]

Traditionally, $\mathrm{BaTiO}_{3}$ Powders are synthesized by two methods: either solid-state reaction or chemically-derived precursors, and these methods produce large, non-uniform, and agglomerating particles. Barium Titanate is considered an attractive material in the field of electric ceramics and microelectronics due to its superior properties, as it was used in many applications in semiconductors, therefore it was prepared and studied due to its importance $[5]$.

\section{Theoretical Part}

The Perovskite, structure is supported by several oxides that have the chemical formula $\mathrm{ABO}_{3}$. Barium Titanate $\left(\mathrm{BaTiO}_{3}\right)$ is a member of the Perovskite family. This structure takes its name from the $\mathrm{CaTiO}_{3}$. The general crystal structure is a primitive cube with the larger A cation in the corner, the smaller B cation in the middle of the cube, and the anion. $\mathrm{O}$ is in the center of the edges of the face where $\mathrm{A}$ is a trivalent mineral, and $\mathrm{B}$ is trivalent or pentavalent elements. The Perovskite structure is considered as a (3D) three framework of $\mathrm{BO}_{6}$ octahedral Figure (1.a), but it can also be considered as a cubic closed pack arrangements of $\mathrm{A}$, and $\mathrm{O}$ ions with the $\mathrm{B}$ ions filling the interstitial positions Figure (1.b) [6].

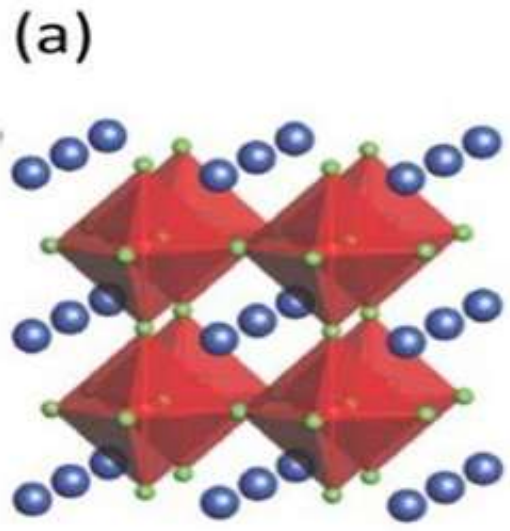

(b)

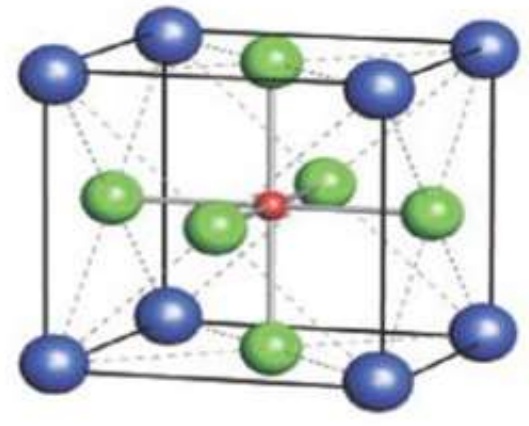

Figure 1: Perovskite cubic structure $\mathrm{ABO}_{3}$, (a) Three dimension perovskite structure,(b) Cubic close packed structure [6].

Barium Titanate has been an interesting material for more than 60 years, due to it is properties. Firstly, its properties are chemically and mechanically stable, secondly, due to its ferroelectric properties at room temperature, and finally, because it is used in the form of polycrystalline ceramics samples and can be easily prepared at low cost [7]. $\mathrm{BaTiO}_{3}$ is one of the important ferroelectrics materials [8]. It belongs to perovskite as ceramics so it needs ultrafine powders $\left(\mathrm{BaTiO}_{3}\right)$ to reduce (calcination temperature, porosity, sintering time, and sintering temperature) [9]. All the above parameters will lead to less cost by reducing the energy and increasing efficiency. Barium Titanate is the first ferroelectric perovskite substance to be discovered. Barium Titanate has Varieties of ferroelectric properties with structural phase transitions. The Curies points $\left(\mathrm{T}_{\mathrm{C}}\right)$ of $\left(\mathrm{BaTiO}_{3}\right)$ is about $1200{ }^{\circ} \mathrm{C}$. Figure (2) illustrates the phase changes of Barium Titanate $\left(\mathrm{BaTiO}_{3}\right)$. 


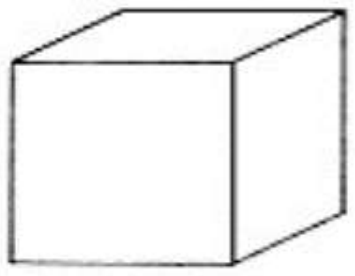

(a)

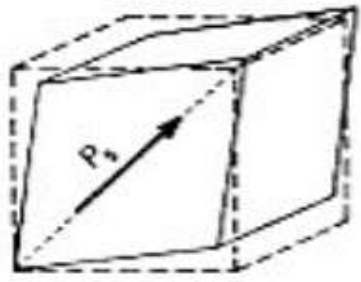

(c)

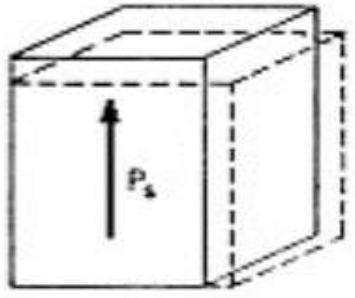

(b)

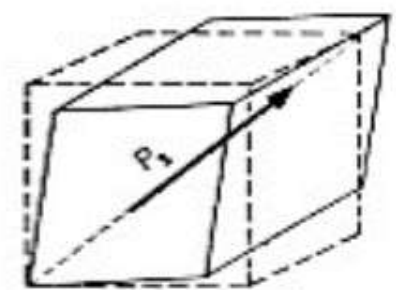

(d)

Figure 2: unit cell of four phases of Barium Titanate, (a) cubic phase above curie point $(120){ }^{\circ} \mathrm{C}$, (b) tetragonal phase occurs between $(5<\mathrm{T}<120){ }^{\circ} \mathrm{C}$, (c) orthorhombic phase stable at $(-90<\mathrm{T}<-5){ }^{\circ} \mathrm{C}$, (d) Rhombohedral phase this phase-stable below $\mathrm{T}=-90{ }^{\circ} \mathrm{C}[6]$.

Cubic phase: this phase occurs above curie temp. $\left(120^{\circ} \mathrm{C}\right)$ and has random polarization[ 10$]$. At $120^{\circ} \mathrm{C}$ titanium ions in the center of the structure, thermal vibration is sufficient to produce random orientation it is octahedral, interstitial position in Barium Titanate $\left(\mathrm{BaTiO}_{3}\right)$.

Tetragonal phase: this phase occurs below $\left(120^{\circ} \mathrm{C}\right)$. It is stable between $(5<\mathrm{T}<120)^{\circ} \mathrm{C}[11]$.

Orthorhombic phase: this phase occurs when $\mathrm{T}=5^{\circ} \mathrm{C}$, and it is stable between $(-90<\mathrm{T}<-5)^{\circ} \mathrm{C}[12]$.

Rhombohedral phase: this phase occurs below $\mathrm{T}=-90^{\circ} \mathrm{C}$.

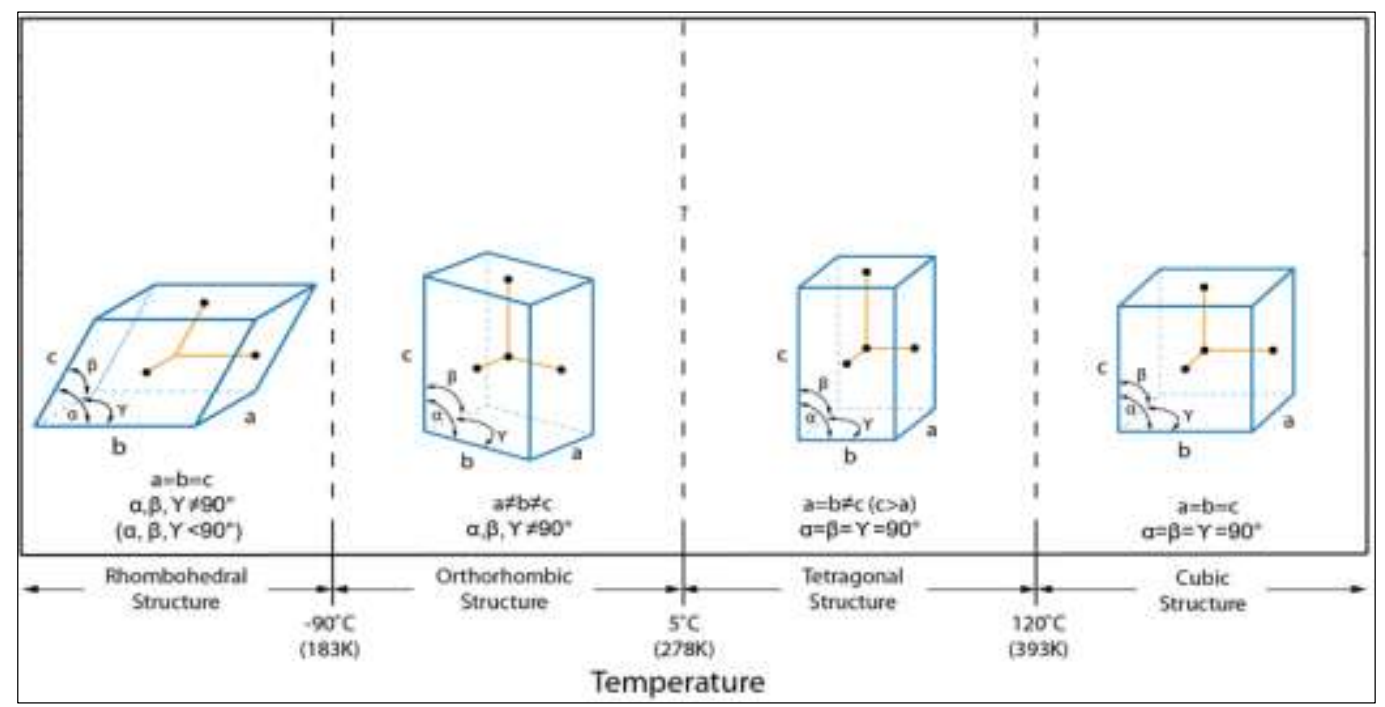

Figure 3: Phase transformations of pure $\mathrm{BaTiO}_{3}$ vs. Temperatures [12]. 
The wide range of applications of Barium Titanate includes preparing multilayers ceramics capacitors MLCCS, electro-optical device, PTC resistors. Piezo-electric actuators, transducers, and chemical gas sensors. [13-18]. We try to discuss the solid-state reaction methods which were used to prepare Barium Titanate $\left(\mathrm{BaTiO}_{3}\right)$ need calcination temperature $(800-1200){ }^{\circ} \mathrm{C}$ [19], but in other works it was $(1350)^{\circ} \mathrm{C}$. Barium Titanate can be used in solar cell because solar energy an alternative source of renewable energy and clean technology for the environment, it is a solution to the humankind environmental problems nowadays [20].

In this work, we prepare the micro Barium Titanate in the easiest and economical way, and its structural properties are studied. Then it is compared with Barium Titanate with Nano scale to know and study the properties, due to the importance of it in the dielectric properties and benefiting from it in most useful application.

\section{Experimental Procedure}

The solid-state reaction is the method used to prepare pure micro Barium Titanate $\left(\mathrm{BaTiO}_{3}\right)$ of 1:1 molar ratio from Barium carbonate $\left(\mathrm{BaCO}_{3}\right)$ and titanium dioxide $\left(\mathrm{TiO}_{2}\right)$ as raw materials, to be mixed through the use of a binder such as ethanol, according to the chemical formula[21]:

\section{$1000^{\circ} \mathrm{C}, 1200^{\circ} \mathrm{C}$

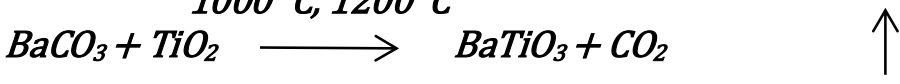

The raw materials of Barium Carbonate $\left(\mathrm{BaCO}_{3}\right)$ and Titanium Dioxide $\left(\mathrm{TiO}_{2}\right)$ were dried by an electric oven (JRAD) for a full 3 hours at a temperature of $(80-90)^{\circ} \mathrm{C}$, to get rid of all the moisture in the raw materials in order not to affect the weight. Weighted Barium Carbonate $\left(\mathrm{BaCO}_{3}\right)$ and Titanium Dioxide $\left(\mathrm{TiO}_{2}\right)$ using a sensitive electrical balance type (Sartorius) with four digits (0.0001) grams. This amount was calculated using the molar ratio of 1:1 mol.

The raw materials (Barium Carbonate and Titanium Dioxide) were mixed through dry mixing and milled by hand mill for 30 min to obtain a fine and more homogeneous powder. The raw materials Barium Carbonate $\left(\mathrm{BaCO}_{3}\right)$ and Titanium Dioxide $\left(\mathrm{TiO}_{2}\right)$ were mixed wet by adding ethanol and grinding balls (porcelain balls) to the powder, which was mixed in a dry form previously, and then put in the Ball milling and grinding for 3 hours to obtain complete homogeneity and evenly overlap the materials. Put the mixture in a container (zirconium crucible) in the oven at a temperature less than $100^{\circ} \mathrm{C}$. This is to evaporate the ethanol from the mixture. The mixture is re-grinded by a hand grinder to obtain a homogeneous powder period of $30 \mathrm{~min}$. The homogeneous mixture is burned by placing it inside the burning crucible made of zirconia at a temperature of (900-1350) ${ }^{\circ} \mathrm{C}$, to obtain the required phase of Barium Titanate (tetragonal), where the temperature should not exceed $1400{ }^{\circ} \mathrm{C}$.

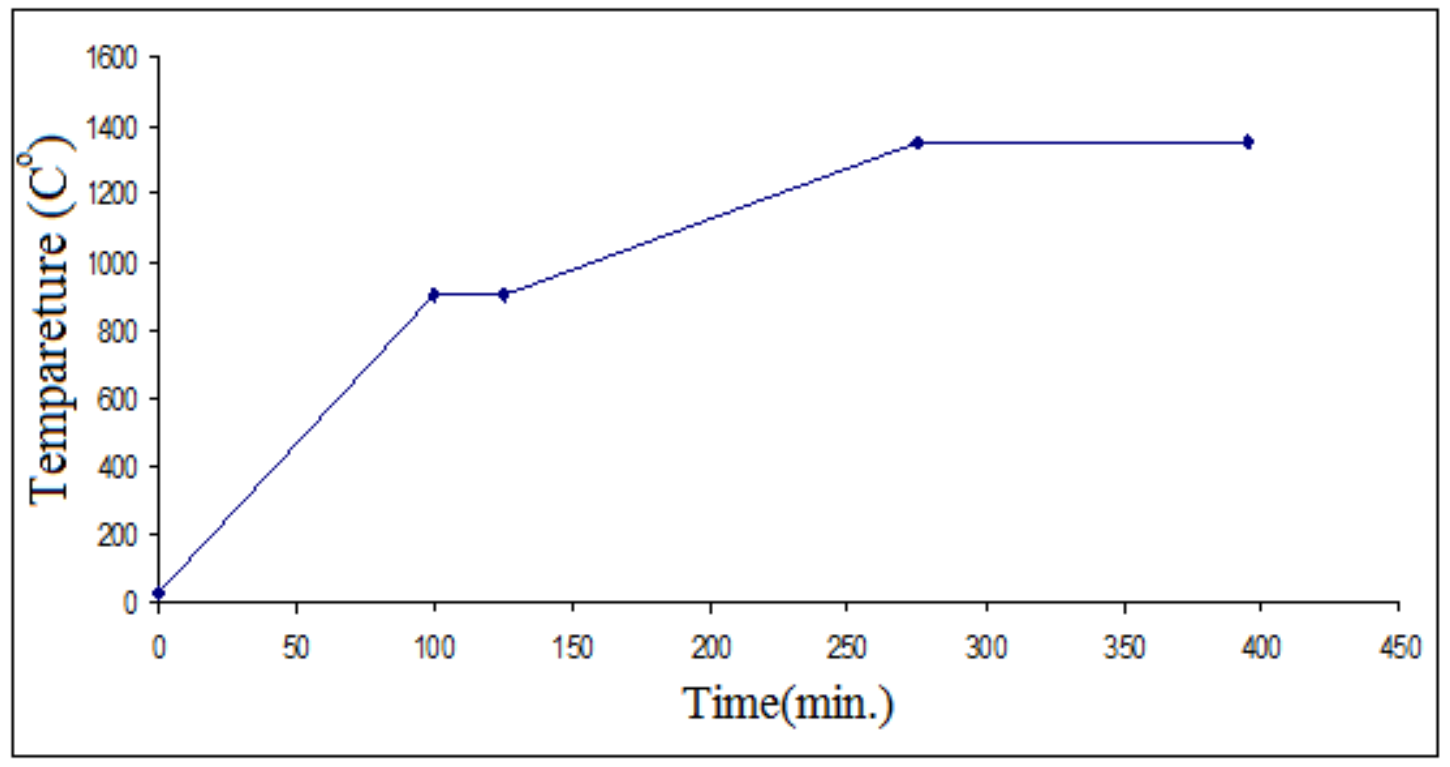

Figure 4: sintering program of pure Barium Titanate vs. time. 


\section{Results and Discussion}

The solid-state reaction needs a nearly high temperature $(1000-1350){ }^{\circ} \mathrm{C}$ then it follows the grinding process. The resulting mini frost has a large grain size and multiple stages i.e. heterogeneous, and is innovatively porous with a sintering temperature about of $1350{ }^{\circ} \mathrm{C}[21]$.

\subsection{X-ray diffraction}

As in pattern matched with the standards pattern of Barium Carbonate (JCPDS No. 000-005-0378) and standards of Titanium Dioxide $\mathrm{TiO}_{2}$ (JCPDS No. 000-021-1272) Figure (5) shows the (XRD) patterns of raw materials $\mathrm{BaCO}_{3}$ and $\mathrm{TiO}_{2}$ before calcinations.

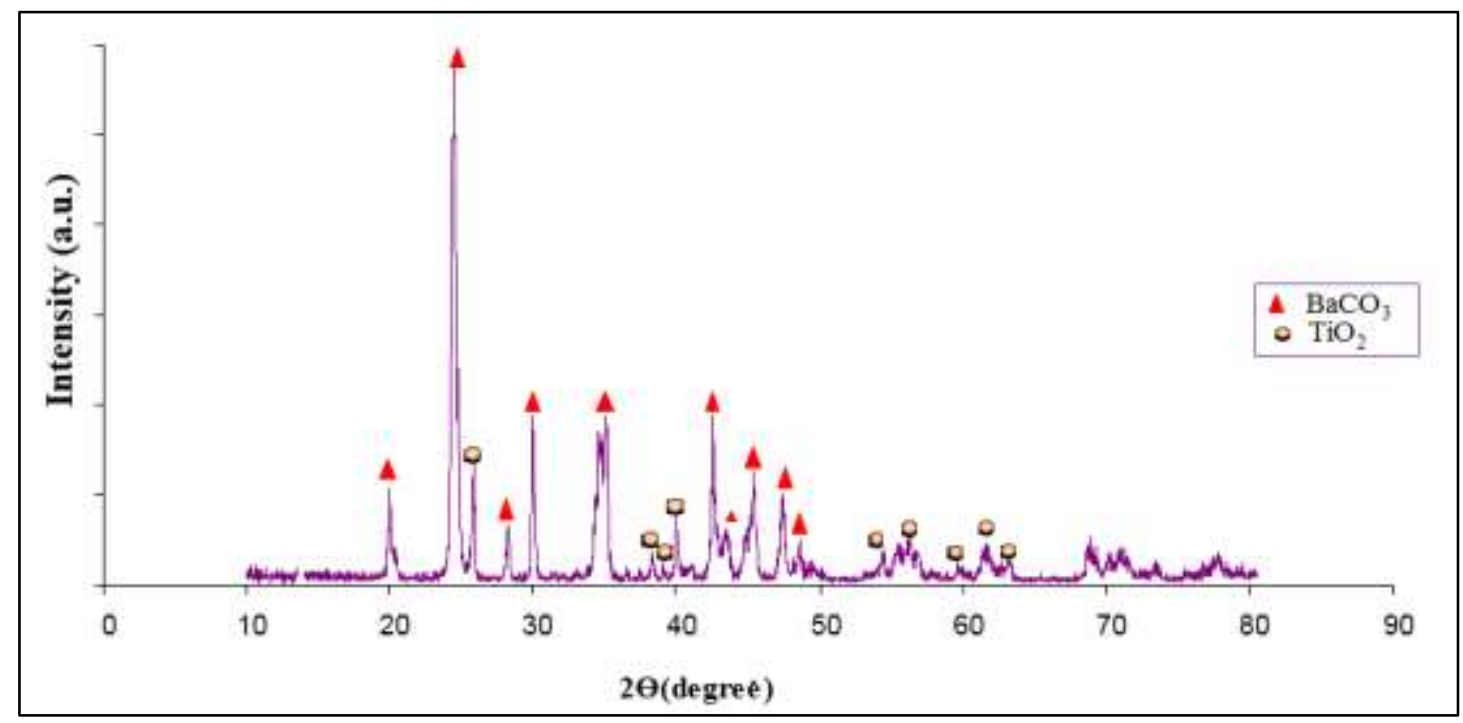

Figure 5: Barium Carbonate $\mathrm{BaCO}_{3}$ \& Titanium oxide $\mathrm{TiO}_{2} \mathrm{XRD}$ pattern before sintering.

The Product of rather uniform Barium Titanium around the titanium Dioxide particles needs to state how the final product retains the initial morphology of the substrate and this implies a rapid transfer mechanism. Such as surface diffusion which provides a constant supply over the entire surface of the particles It is reasonable to use both substrates in the crystalline form which leads to a more familiar contact between Barium Carbonate and Titanium Dioxide. This implies an increase in the number of contact points between the reactants, a decrease of the average transport distance for surface and volume Barium diffusion, and possibly, an increase of the average chemical potential $\mathrm{Of} \mathrm{BaO}$ at the surface of Titanium Dioxide particles. The kinetics of the overall reaction can be affected by each factor [22] 


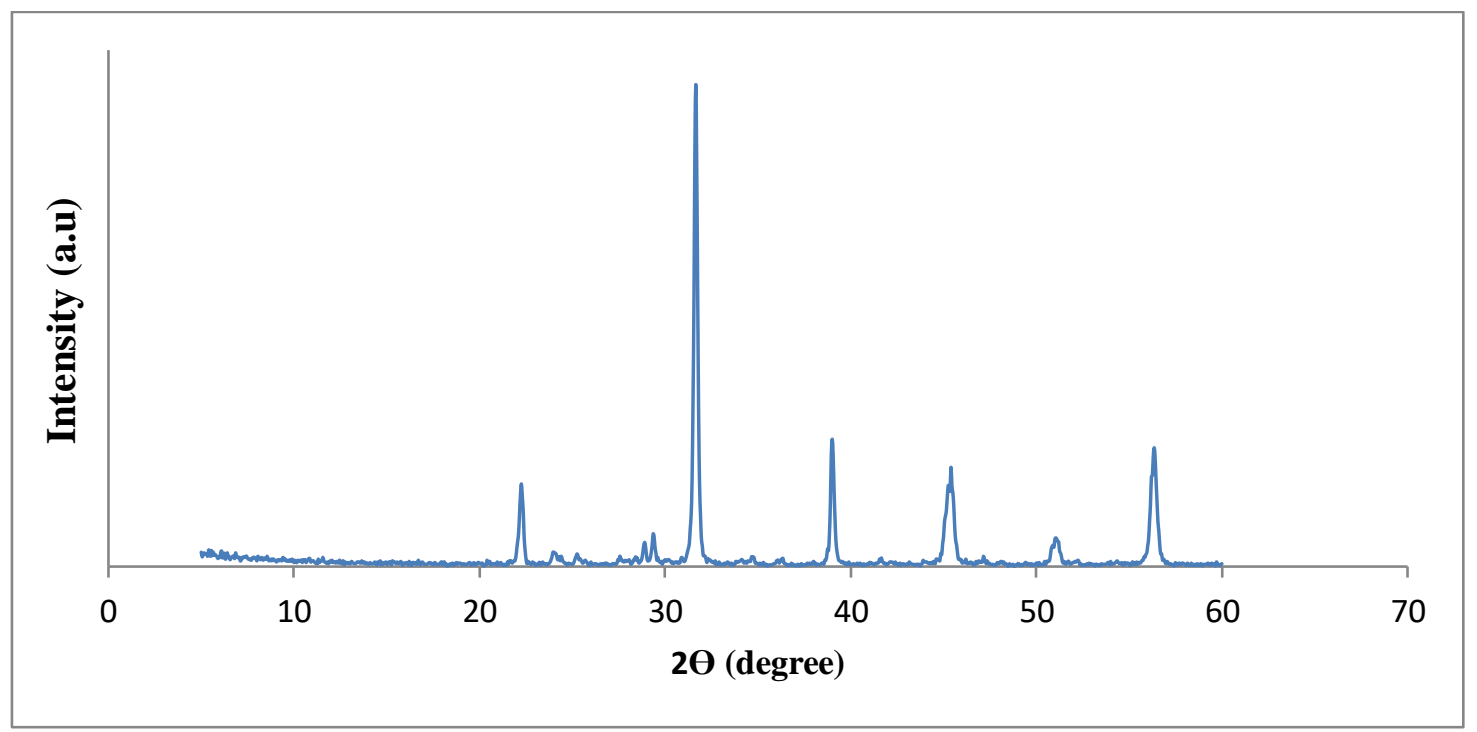

Figure 6: Barium Titanate XRD pattern at $900{ }^{\circ} \mathrm{C}$.

In Figure (6) XRD pattern confirmed the existence of the Barium Titanate with tetragonal phase (the pattern matched with the standard pattern JCPDS No. 05-0626). In Figure (7) at $1000^{\circ} \mathrm{C}$ temperature there was a low intensity of Titanium Dioxide $\left(\mathrm{TiO}_{2}\right)$ but there was no Barium Carbonate.

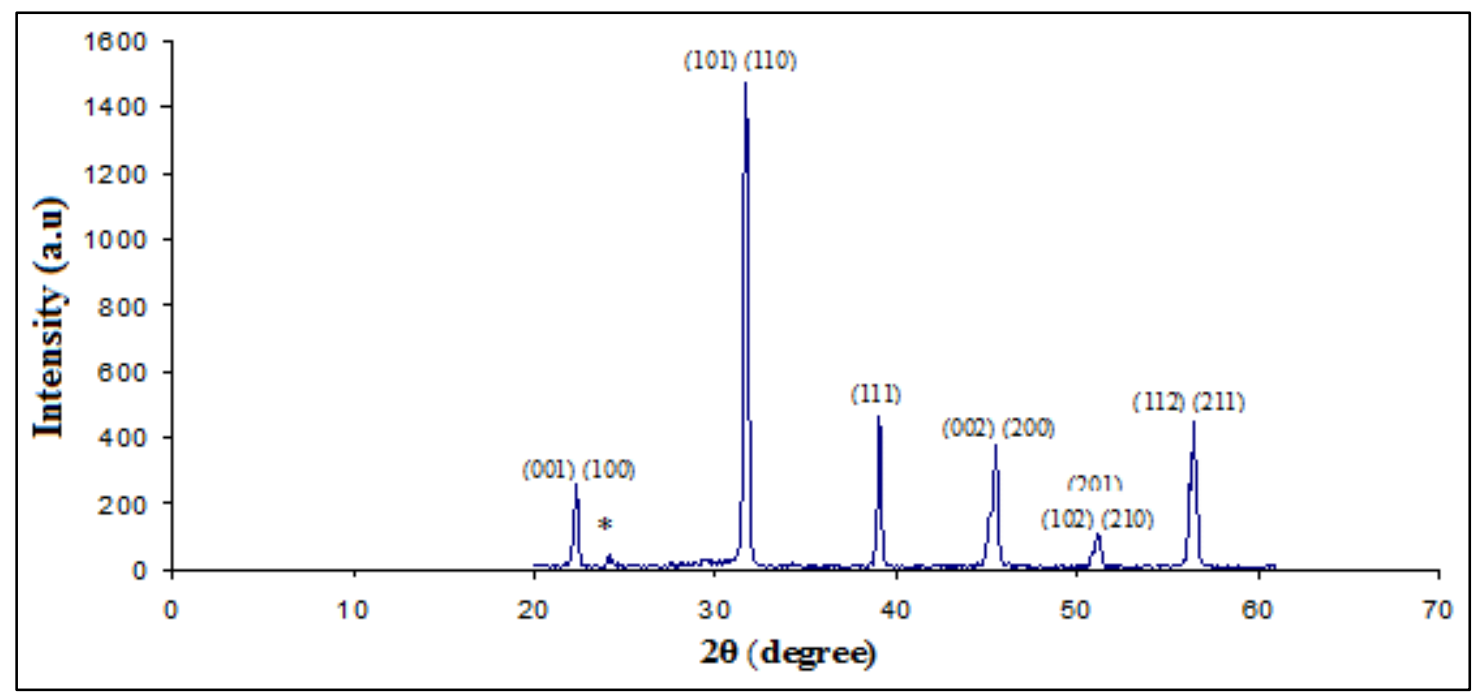

Figure 7: Barium Titanate XRD pattern at $1000^{\circ} \mathrm{C}$.

The symbol $(*)$ refers to the peaks for the Titanium Dioxide this means that the reactions of Barium Titanate are not complete because of the presence of another peak which belongs to Titanium Dioxide $\left(\mathrm{TiO}_{2}\right)$ [23]. 


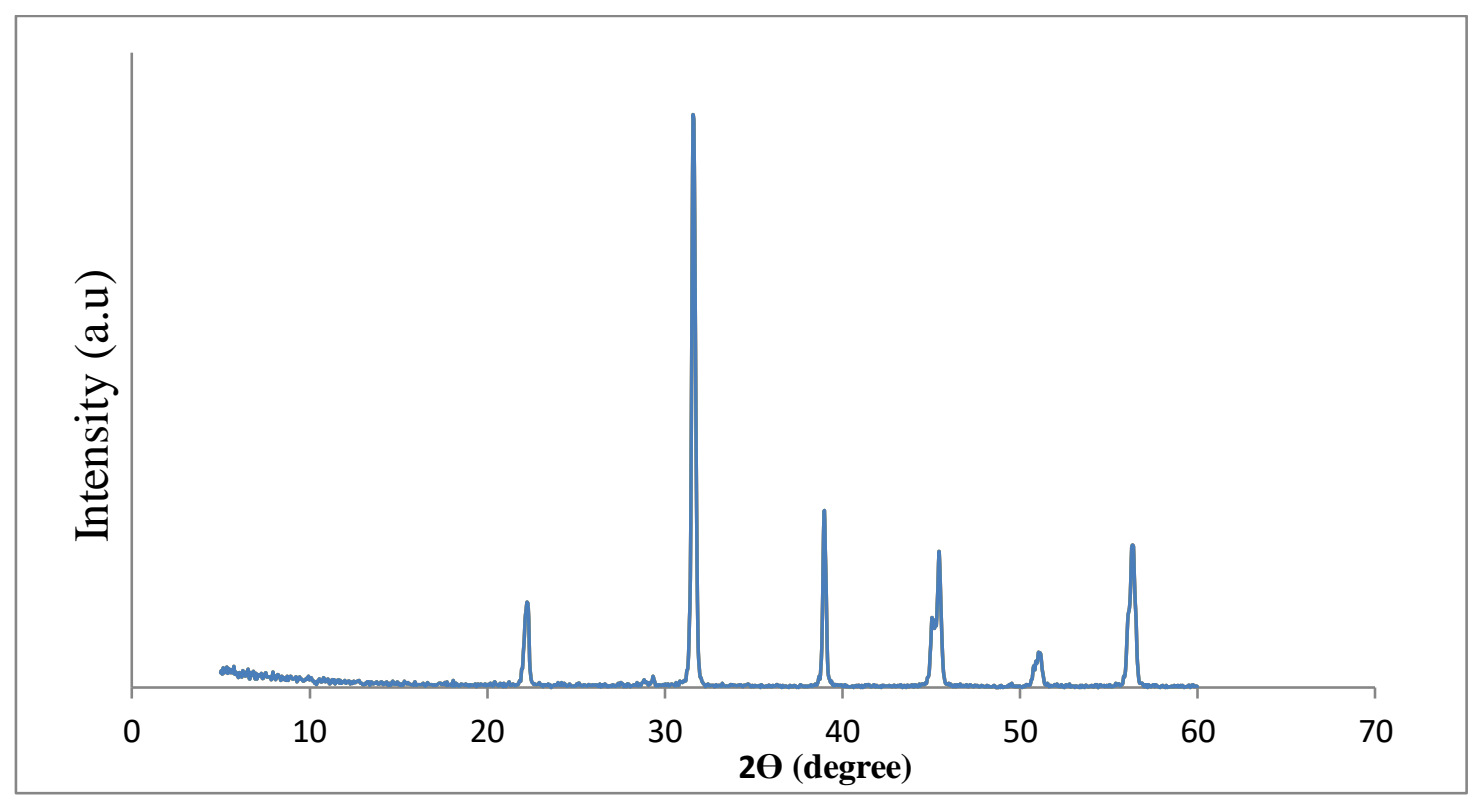

Figure 8: Barium Titanate XRD pattern at $1100^{\circ} \mathrm{C}$.

The first notice indicates that the lattice of the studied structures, at first cubic has undergone a low tetragonal distortion. The second corresponds to increased tetragonal deformation. With increasing temperatures the crystallinity of the sample increases, and in the absence of tetragonal deformation, the width of the XRD peaks should decrease. With the recorded patterns, it is not possible to quantitatively distinguish the peaks broadening because of the size of crystallites from the effect of tetragonal deformation.

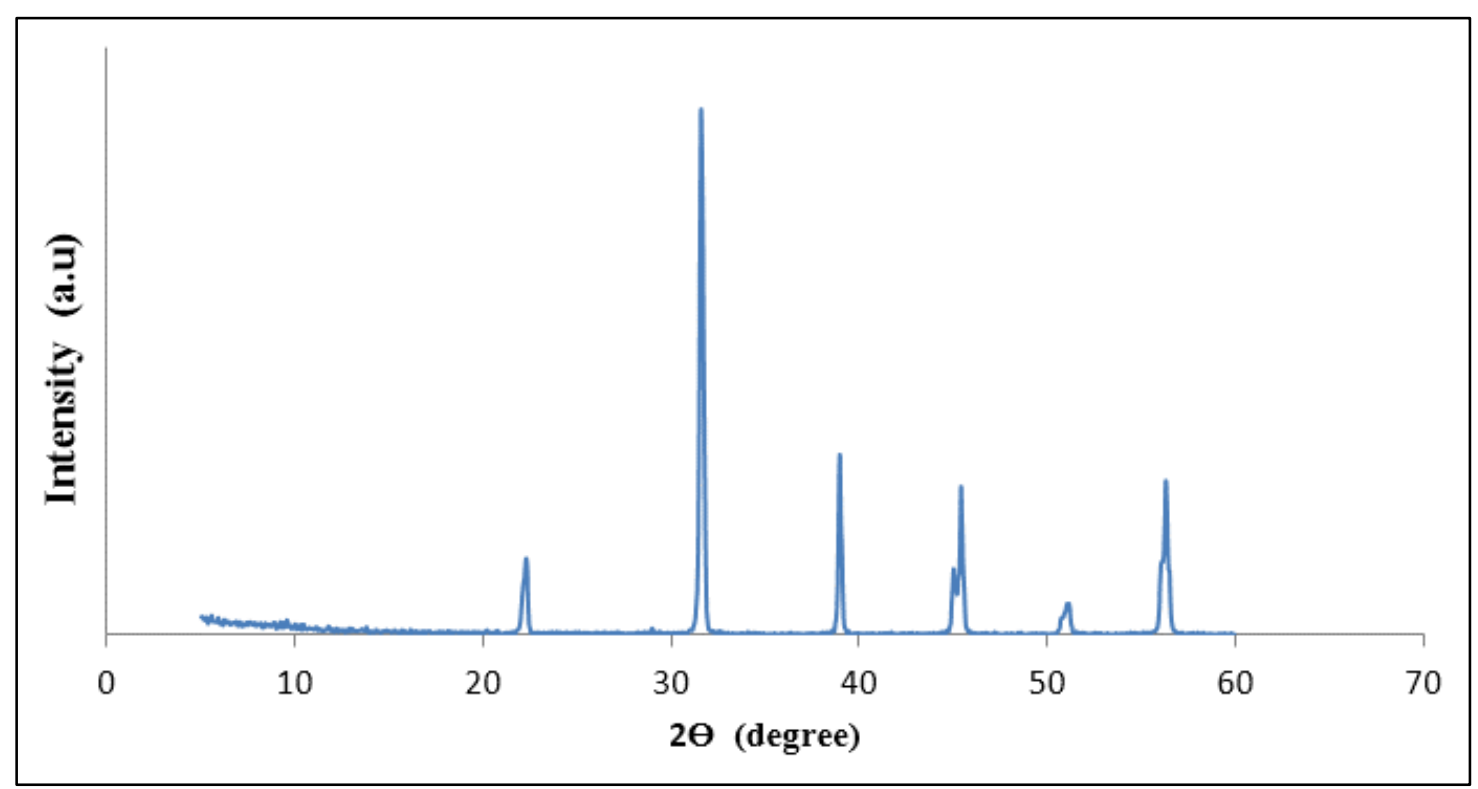

Figure 9: Barium Titanate XRD pattern at $1200{ }^{\circ} \mathrm{C}$.

So as it can be seen they are widened gradually and lastly split during an increase in the sintered temperature. This phenomenon refers to the (tetragonal structure) of Barium Titanate $\left(\mathrm{BaTiO}_{3}\right)$ phase was formed well with the increase in sintered temperature [24]. As shown in Figure (9). 


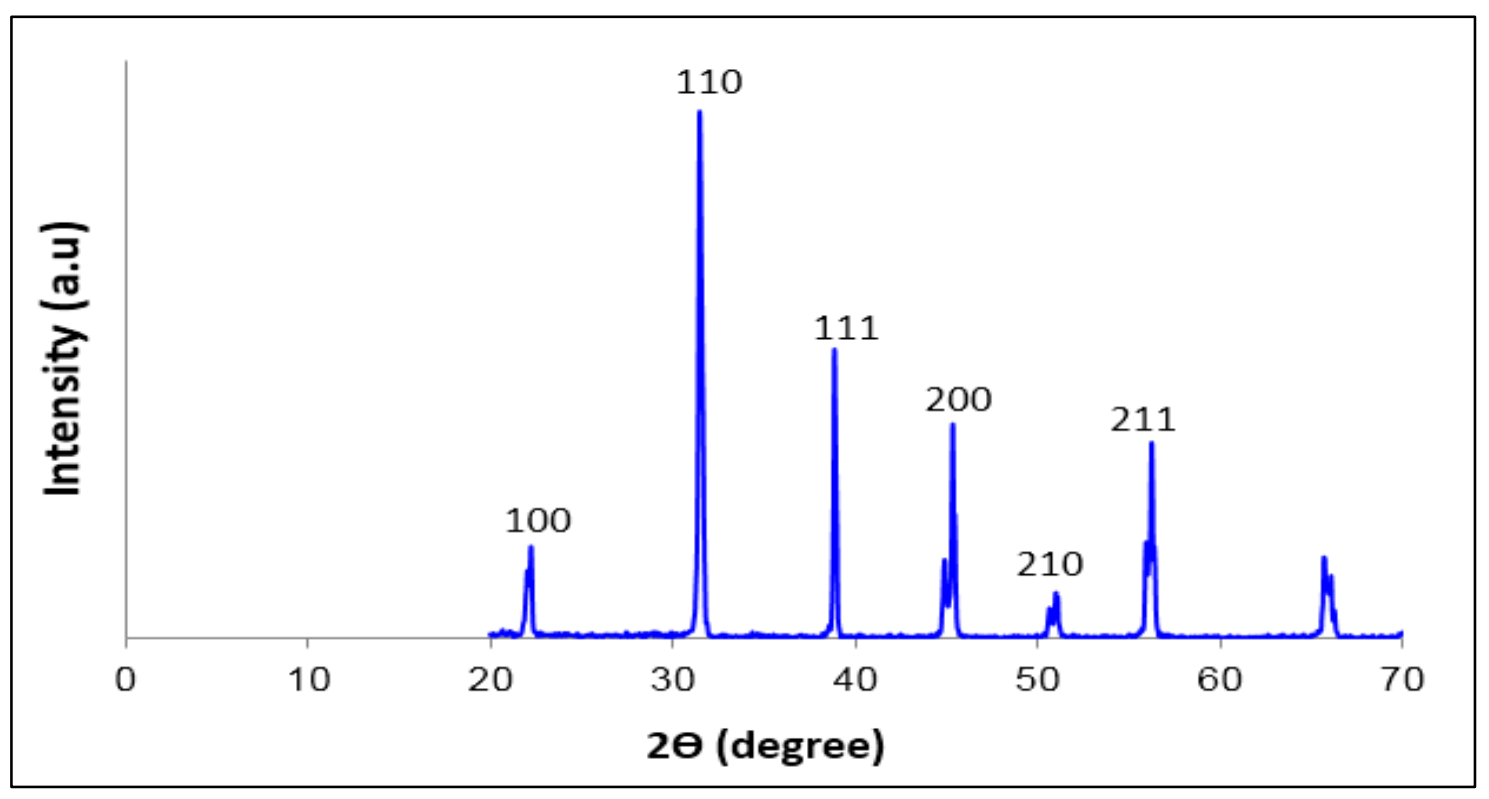

Figure 10: Micro Barium Titanate XRD pattern at $1350{ }^{\circ} \mathrm{C}$.

In Figure (10) which shows a pure sample that sintered at $(1350)^{\circ} \mathrm{C}$, some observed peaks disappear, that happens due to a temperature below the temperature of sintering (which is $1350{ }^{\circ} \mathrm{C}$ for $\mathrm{BaTiO}_{3}$ ceramic ), there are no completed reactions and phases (peaks of remains raw materials that did not reach) shown in X-ray diffraction Pattern as small peak, that extra peaks disappear when reaching sintering temperature because at sintering temperature all the reaction completed and pure phase of Barium Titanate become more noticeable.

This phenomenon refers to the (tetragonal structure) of Barium Titanate $\left(\mathrm{BaTiO}_{3}\right)$ phase which was formed well with the increase in sintered temperature[ 25, 26].

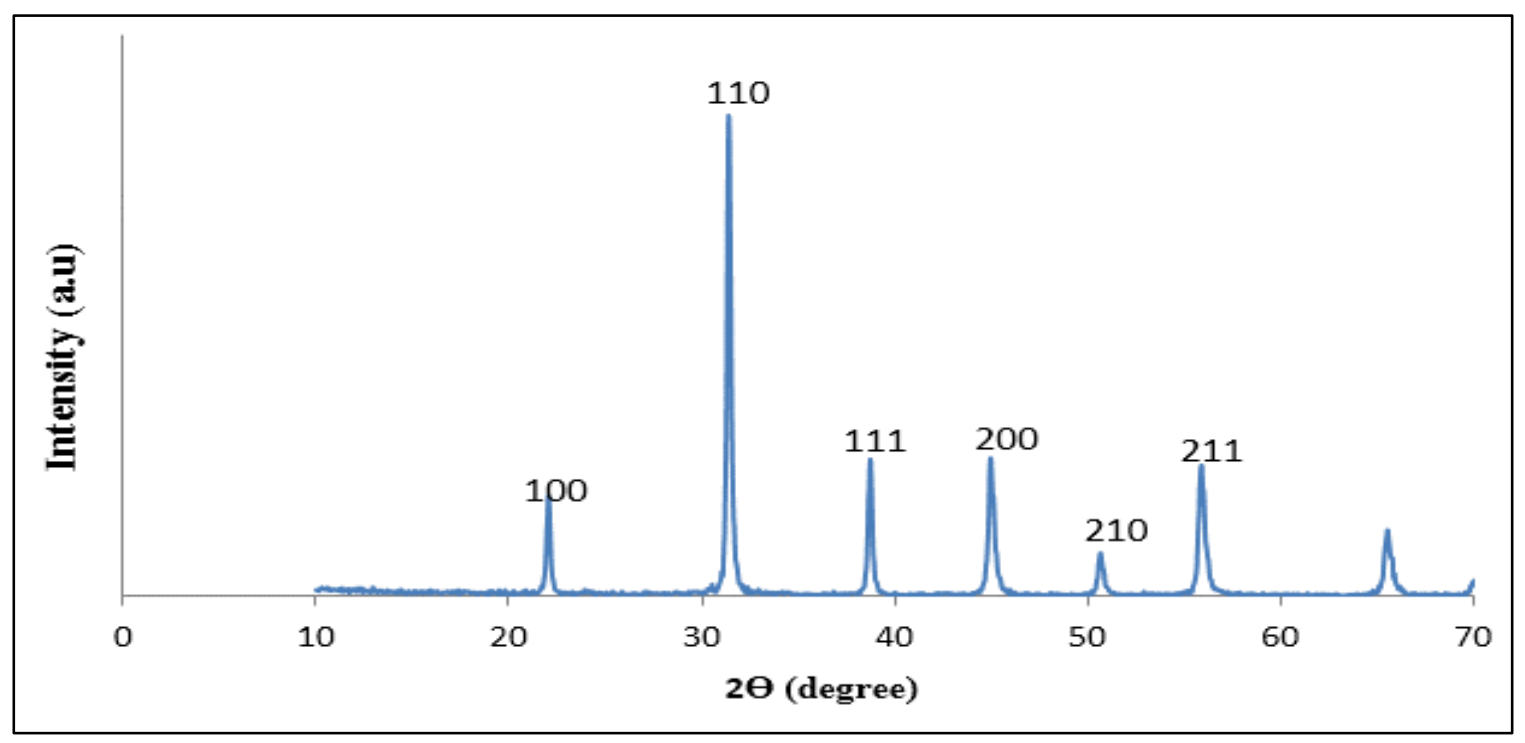

Figure 11: Nano-Barium Titanate XRD pattern. 
In the Figure (11), the X-ray pattern of Barium Titanate nanoparticles is shown, we notice in the figure the peaks of Nanopowder appear before (shift to the large angle) the peaks that appear in the micro-powder.

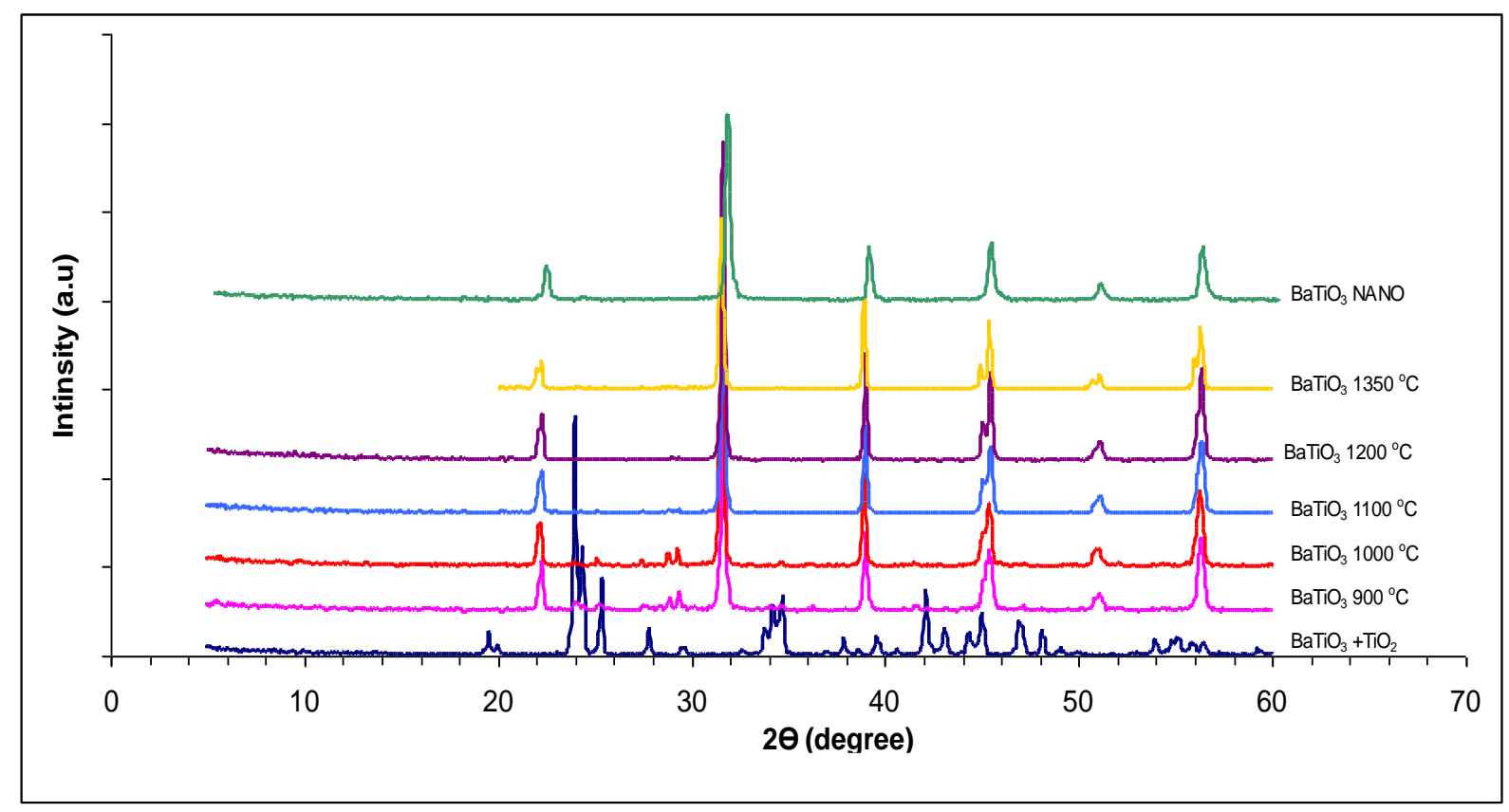

Figure 12: XRD pattern for pure micro \& nano Barium Titanate with different temperatures.

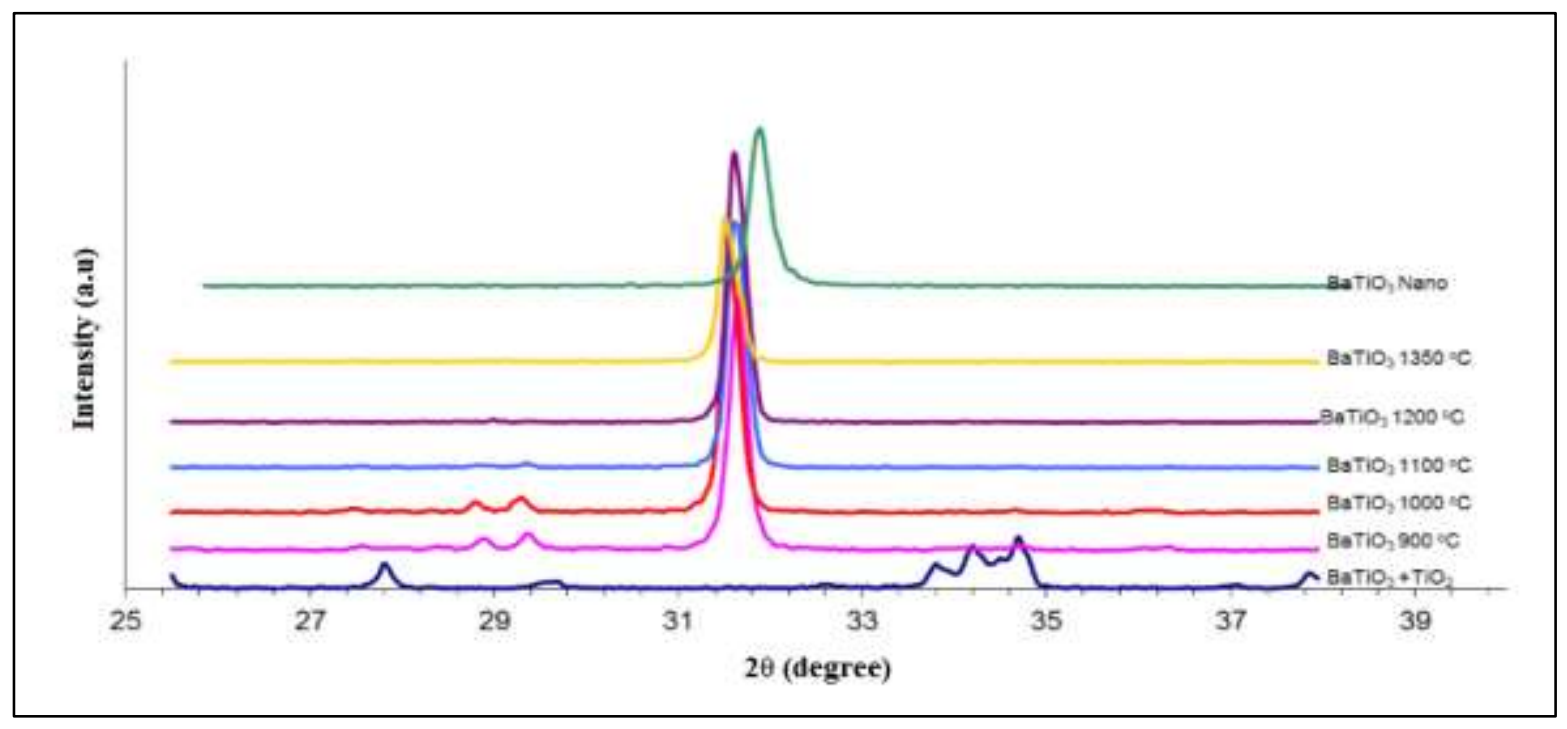

Figure 13: Illustrates shifting in the peaks of XRD patterns for pure micro and nano $\mathrm{BaTiO}_{3}$.

As shown in Figure (12)(13), from the XRD patterns, the Nanopowder of Barium Titanate $\left(\mathrm{BaTiO}_{3}\right)$ when compared with micro-powder of Barium Titanate notice that there are shifting in the peak to the large angle (to the right) and this is true because when the particle size small (Nanopowder) the shifting will be to the large angle.

\subsection{Scanning Electron Microscopy}

Note from Figure (14-a-d) of micro and Nanopowder with different magnification, scans show that the samples are cubic $\mathrm{BaTiO}_{3}$, which form spherical particles[27,28]. this is in agreement with the results obtained from XRD patterns, there are shifting with Nano compared with micro. 

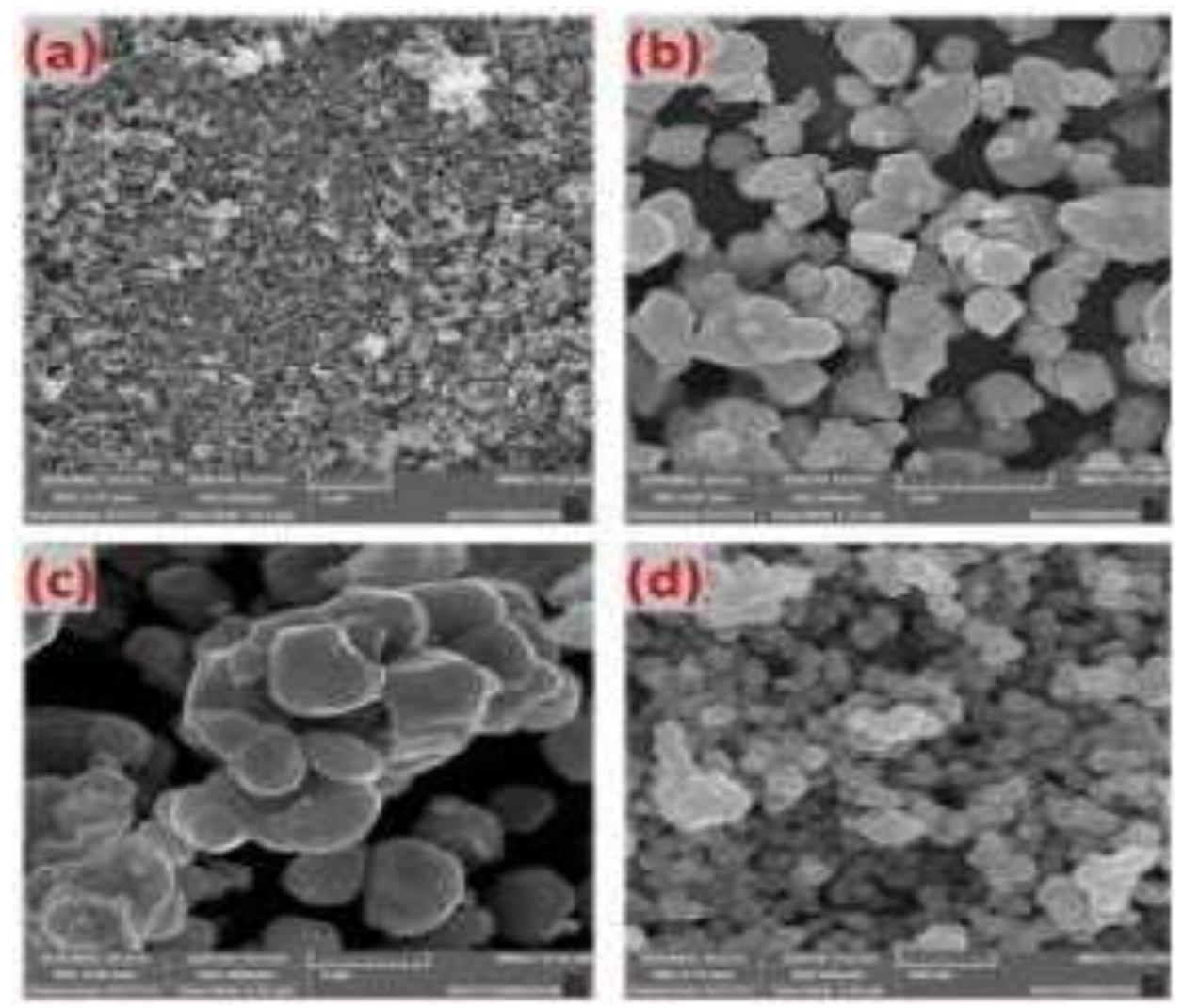

Figure 14: Scanning electron microscopy for (micro\& Nano $\mathrm{BaTiO}_{3}$ ) powders with different magnification,(a) SEM magnification 10.0X, $2 \mu \mathrm{m}$, (b) SEM magnification 20.0X, $2 \mu \mathrm{m}$, (c)SEM magnification $30 \mathrm{X}, 1 \mu \mathrm{m}$, (d) SEM magnification $50.0 \mathrm{X}, 500 \mathrm{~nm}$.

The SEM images, show the particle size and agglomerations possibility. Some of these particles seem larger than the original may be due to the upper limit of the Scherrer's formula of about $100 \mathrm{~nm}$ [29].

\section{Conclusions}

In this study, we observed pure micro Barium Titanate has been synthesis by solid-state reaction of pure crystalline $\left(\mathrm{BaCO}_{3}\right)$ and Titanium Dioxide $\left(\mathrm{TiO}_{2}\right)$, and this method can be considered as an attractive process realistic alternative to more expensive wet-chemical route, we conclude that according to X-ray diffraction. XRD patterns for this method appear all the peaks of Barium Titanate $\mathrm{BaTiO}_{3}$ and with prefer crystalline size for the powder calcined at $1350^{\circ} \mathrm{C}$ all peaks refer to the formation of Barium Titanate completely. by comparing each of the Nanopowder of $\mathrm{BaTiO}_{3}$ with prepared micro powder that calcined at $1350{ }^{\circ} \mathrm{C}$, by conducting x-ray diffraction, diffraction peaks undergo shifting toward higher angle (to the right) because of the Nanopowder particles which are smaller than micro powder and this refers to a decrease in lattice parameters, in terms of the peaks of the Nanopowder preceding the peaks of the micro powder of $\left(\mathrm{BaTiO}_{3}\right)$.

\section{Acknowledgement}

Thanks to God for helping us in this work, and I would like to thank the Department of Applied Sciences for their help and support, Material engineering department, nanotechnology and advanced material research center

Conflict of Interest: The authors declare that they have no conflict of interest.

\section{References}

[1]M. Boulos, S. Guillement-Fritsch, F. Mathieu, B. Durand, et al.," Hydrothermal synthesis of Nano sized BaTiO3 powders and dielectric properties of corresponding ceramics," Solid State Ionics, vol.176, No. 4, p.1301-1309, 2005. 
[2]B. Szafraniak, Ł. Fusnik, J. Xu, F. Gao, A. Brudnik, A. Rydosz, et al., "Semiconducting Metal Oxides: SrTiO3, BaTiO3 and BaSrTiO3 in Gas-Sensing Applications: A Review. Coatings," MDPI: Coatings, Vol.11, No. 4, P.185, 2021.

[3]D. Yoon, "Tetragonality of barium titanate powder for a ceramic capacitor application," Journal of Ceramic Processing Research, Vol. 7, No. 4, P. 343, 2006.

[4] S. M. A. Ridha and M. M. Najim, "Synthesis and Study the Dielectric Properties of La-Doped and Undoped Barium Titanate Nanopowders,” MSC, Institute of Materials Science, Iraq, 2015.

[5] B. D. Stojanovic, C. R. Foschini, V. B. Pavlovic, V. M. Pavlovic, V. Pejovic, et al., "Barium titanate screenprinted thick films," Ceramics International,Vol. 28, No. 3, P. 293-298, 2002.

[6] J. M. Hwu, W. H. Yu, W. C. Yang, Y. W. Chen, Y. Y. Chou, et al., "Characterization of Dielectric Barium Titanate Powders Prepared by Homogeneous Precipitations Chemi- cal Reaction for Embedded Capacitor Applications," Materials Research Bulletin, Vol. 40, No. 10, P. 1662-1679, 2005.

[7] A. Ianculescu, A. Brileanu, M. Crian, P. Budrugeac, et al., "Influence of Barium source on the characteristics of sol-precipitated BaTiO3 powders and related ceramics," Journal of Thermal Analysis and Calorimetry, Vol. 88, 1,P. 251-260, 2007.

[8]F. Guangneng, H. Lixia and H. Xueguang, "Synthesis of Single Crystal BaTiO3 Nanoparticles via One Step Sol- Precipitation Route,” Journal of Crystal Growth, Vol. 279, No.3, P. 489-493, 2002.

[9]Z. Chen, W. Zhang, J. Chen and Y. Jimmy, "Low Tem-prelature One Step Synthesis of Barium Titanate: Particle Size Mechanism and Large Scale Synthesis," Chinese Journal of Chemical Engineering, Vol. 14, No. 5, p. 642-648, 2006.

[10] L. Simon-Seveyrat, A. Hajjaji, Y. Emziane, and B. Guiffard, D. Guyomar," Re-investigation of synthesis of BaTiO3 by conventional solid-state reaction and oxalate precipitation route for piezoelectric applications," Ceram. Int., Vo. 33, No. 1, p. 35-40, 2007.

[11] X. Hurarui and G. Lain, "New Evidence of a Dissolution Precipitation Mechanism in Hydrothermal Synthesis of BaTiO3 Powder," Material Letters, Vol. 57, No. 2, P. 490-494, 2002.

[12] N. Xu, Y. Lu, Y. Liu, Sh. Shi, T. Qian, D. Lu, et al., " Chemical Synthesis of Mono sized Spherical BaTiO3 Particles," Power Technology, Vol. 161, No. 1, P. 185-189, 2006.

[13] H. Xu, L. Geo and J. Guo, "Preparation and Characterizations of Tetragonal BaTiO3 by Hydrothermal Method," Journal of European Ceramic Society, Vol. 22, No. 7, P. 1163-1170, 2002.

[14] Y. Khollam, A. Deshpande, H. Potdar, S. Deshpande, A. Patil, et al.,"A Self Sustaining Acid Base Reaction in Semi-Aqueous Media for Synthesis of Barium titanyl Oxalate Leading to BaTO3 Powder," Material Letters, Vol. 55, No. 2, P. 175-181, 2002.

[15] H. Xu, L. Gao , and J. Am." Tetragonal Nano crystalline Barium titanate powder: preparation, characterization and dielectric properties, " Ceramics International, vol. 86, No. 1, P. 203-205, 2003.

[16] L. Wang, L. Liu, D. Xue, H. Kang, C. Liu, J. " wet routes of high purity BaTiO3 Nano powders," Journal of Alloys and Compounds, vol.440, No. 2, P 78-83, 2007.

[17] Shaima K. Abdulridha, Saad A. Tuma, and Omar A. Abdulrazzaq, "Study of the Partial Shading Effect on the Performance of Silicon PV Panels String," Journal of Applied Sciences and Nanotechnology, Vol.1, No.1 ,p. 32-42, 2021. 
[18] R. E. Dinnebier and S. J. L. Billinge, "Powder diffraction theory and practice," The royal society of chemistry (RSC), Vol.15, No. 42, P. 256-267, 2009.

[19] Yanqing Liu, Yuhan Wu, Dan Li, Yongjun Zhang, et al. ," A study of structural, ferroelectric, ferromagnetic, dielectric properties of $\mathrm{NiFe} 2 \mathrm{O}$-BaTiO3 multi Ferro composites," Journal of Materials Science: Materials in Electronics, Vol. 24, P. 1900-1904, 2013.

[20] M. Teresa Buscaglia, M. Bassoli, and V. Buscaglia," Solid-State Synthesis of Ultrafine BaTiO3 Powders from Nano crystalline BaCO3 and TiO2," Journal of the American Ceramic Society, vol.88, No.9, P. 23742379. 2005.

[21] W.Cai, L.Fu, and C..Zhao, "Dielectric properties and micro structure of Mg doped Barium Titanate ceramic," Advance in Applied Ceramic, Vol. 52, No.22, p. 181-185, 2011.

[22] M. Garcia - Hernandez, G. Chadeyon, and D. Boyer. "Hydro thermal synthesis and characterization of Europium - doped Barium Titanate Nano crystallites,"Nano-micro letter, Vol.5, No.23, P.57-65, 2013.

[23] M. M. Vijatović, J. D. Bobić, and B. D. Stojanović, " History and Challenges of Barium Titanate: Part I," Science of Sintering, Vol. 40, No.4, P.155-165, 2008.

[24] P. Pankaj Khirade, Shankar D. Birajdar a , A.V. Raut b , et al.," Multiferroic iron doped BaTiO3 Nano ceramics synthesized by sol-gel auto combustion: Influence of iron on physical properties,"Ceramics International, Vol. 42, No.4, P.11,2016.

[25] X. Wei, Y. Su, Y. Sui, Q. Zhang, Y. Yao, C. Jin, et al., "Structure, electrical and magnetic property investigations on dense Fe-doped hexagonal BaTiO3," Journal of Applied Physics, Vol.110, No.3, P. 114112,2011 .

[26] Kim Y -II, Jung JK, Ryu KS, "Structural study of Nano BaTiO3 powder by Riveted refinement," Mater Res Bull, vol. 39, No.2, p. $1045-1053,2004$.

[27] Maha A Al-Kinani, Adawiya Haider, and Sharafaldin Al-Musawi," Study the Effect of Laser Wavelength on Polymeric Metallic Nano carrier Synthesis for Cur cumin Delivery in Prostate Cancer Therapy: In Vitro Study," Journal of Applied Sciences and Nanotechnology, Vol. 1, No.1, P.43-50 , 2021.

[28] Abbas Khammas, Thear Tarish, andAbdul Raidha; Ali Khudair, "Evaluation of Hot Corrosion Properties for Nano-coated Super alloy ," Journal of Applied Sciences and Nanotechnology, Vol.1, No.1, P. 7-14, 2021.

[29] M.T. Buscaglia, V. Buscaglia, M. Viviani, and P. Nanni, M. Hanuskova," Influence of Foreign Ions on the Crystal Structure of BaTiO3," Journal of the European Ceramic Society, vol.20, No.3, p. 1997-2007, 2000. 